\title{
Impact of Covid-19 on Zambia's 2020 General Education Examination Candidates' Academic Performance in Lusaka: E-Learning Issues
}

\author{
Chrine C. Hapompwe ${ }^{1}$, Crispin Kukano² \& Jacqueline Siwale ${ }^{3}$ \\ Faculty of Arts, Education and Social Sciences \\ Cavendish University Zambia. \\ DOI: 10.29322/IJSRP.10.05.2020.p10175 \\ http://dx.doi.org/10.29322/IJSRP.10.05.2020.p10175
}

\begin{abstract}
The main purpose of this study was to explore the eminent 2020 negative impact of COVID-19 on grades 7, 9 and 12 learners' national examinations results following the premature closure of all schools on $20^{\text {th }}$ March 2020 by government of the Republic of Zambia. The study was exploratory incorporating a qualitative paradigm and involved semistructured key informant interviews of 3 district, provincial and MoGE HQ education officials; 4 primary and secondary school head teachers; 4 members of the parents and teachers' association, in Lusaka via telephone calls; 6 examination candidates; observation and monitoring of the Edu.tv lesson programme by MoGE, desk reviews and expert analysis. Random and purposive sampling were the criteria involved to ensure sample representativeness and therefore validity, reliability and generalizability of findings. The findings converged factually that COVID-19 had enormous terrible impact on the quality of general education of the sector as a whole, but would greatly further dwindle the already average academic performance of learners in public schools. Among the vital views heralded by interviewees were the fact that although the Edu.tv broadcast programme was from initiation encumbered with barriers of accessibility by many learners as not all homes had TV sets nor internet access for online materials, it was also compounded by the 12-hour daily electricity load shedding schedule invoked by the local power utility company. Besides, the programme had reduced contact duration per subject and did not cover the grade 7 examination candidates or the entire primary school level. Furthermore, the materials for learners with disabilities were at the time not made available despite the fact they were part and parcel of the 2020 examinations candidates and that the Edu.tv programme lacked interactionism and experientialism to facilitate learner attention, material retention, assimilation and absorption. The study strongly urges the MoGE to urgently repackage and diversify the Edu.tv broadcast learning platform in order to make it accessible, equitable, dynamically intriguing and experientially insightful as per the social cognitive and experiential learning theories' prescriptions respectively. The programme also should be availed to more electronic /digital platforms to enable all learners access it while rural areas must be given preferential treatment with user friendly materials which are largely non-electronic. The grade 7 examination class which is currently eclipsed from This publication is licensed under Creative Commons Attribution CC BY.

the e-learning programme must be considered and provided for while learners with disabilities also need urgent attention as they will write similar final examinations with those without disabilities. Over and above, it would be prudent for government to closely monitor the pandemic's escalation and possibly consider partial re-opening of schools for examinations classes with schools' strict adherence to public health rules invoked should the situation be permissible in order to avert the eminent poor academic performance.

Key words: Academic Performance, COVID-19 and Impact.

\subsection{INTRODUCTION}

The world at large deems education as a basic human right and the basis upon which to build peace, harmony, national progress and sustainable development (UNESCO, 2018). This profound conception is equally posited and heralded by the Southern Africa Development Community (SADC) - a regional body to which Zambia subscribes. However, the COVID-19 global pandemic has caused untold misery to the prospects of brighter future for the education sector globally but particularly in Zambia. The acronyms COVID-19 simply stands for Coronavirus disease discovered in 2019. COVID-19 is a respiratory viral disease transmitted through droplets of an infected person when s/he sneezes or coughs. In response to this global public health pandemic and as mandated by the Public Health Act Cap 295 of the Laws of Zambia and as guided by two Statutory Instruments, SI 21 and SI 22, both issued on $14^{\text {th }}$ March, 2020, the Government of the Republic of Zambia through the Minister of Health, on $17^{\text {th }}$ March 2020, solemnly issued a pre-mature closure notice of all schools, colleges and universities in Zambia with effect from Friday, $20^{\text {th }}$ March 2020 as a measure to curb the supersonic spread of COVID-19. At the time of the SIs invocation, COVID-19 was reported to have spread to 162 countries with 181,335 cases and 7,130 deaths globally (Ministry of Health Press Statement, 17 th March, 2020). By the closure notice which the Ministry of General Education (MoGE) effected and actualized to all learning institutions as per their circular dated $18^{\text {th }}$ April, 2020, all pupils in all schools were to leave school premises to their various homes in compliance 
with the closure notice at such a time before writing their end of term assessments while 2020 candidates' examination registration was still in progress.

Against this background, this study was purposed to investigate the potential impact of COVID-19 on academic performance of general education examination candidates in Lusaka district of Zambia, premised on the period of pre-mature closure, which has epitomized endemic social, economic and structural bottlenecks in efficient and effective delivery of alternative Edu.tv service to the general education learners populace thereby ultimately prejudicing the country's human capital development prospects as envisioned and enshrined in both the 7NDP and the Vision 2030 (Masaiti et al., 2018; UNESCO, 2018; ESSP, 2017-2022; World Bank, 2018; Hapompwe et al., 2020b, and ZANEC, 2019).

\subsection{Problem Statement}

There is little or almost no documented academic literature available about the Coronavirus as even the medical experts in the medical fraternity globally are still involved in rigorous laboratory tests to ascertain cure and the actual transmissions of the disease (Sintema, 2020). In Zambia, at the time of preparation of this paper, only one study could be spotted having been done by a doctoral student in Spain focusing on the potential effects of COVID-19 on grade 12 candidates' academic performance in Mathematics, Science, English, Design and Technology in Chipata district of Eastern Province of the country. However, the difference with the current study is that the previous study was conducted prior to any reported cases in Zambia (hence, largely speculative) and the launch of the Edu.tv alternative learning platform (indictedly encumbered) in addition to the fact that it only focused on a single grade in a smaller isolated district and case studied a school. The current study is being carried out when the disease toll and death cases are rising in the country to 61 and 3 respectively with a target of over 144 schools and a broad selection of respondents covering all structures of the education system in Zambia. These gaps, therefore, make of essence and relevance the current study as Lusaka has the highest number of schools in the country and the findings might be representative of the phenomena country-wide.

\subsection{Study Objectives}

\subsubsection{Main Objective}

- To explore the eminent 2020 impact of COVID-19 on grades 7, 9 and 12 learners' national examinations academic performance following the pre-mature closure of all schools.

\subsubsection{Specific Objectives}

(i) To investigate the potential effects of COVID-19 on the 2020 general education learners' academic performance in national examinations.

(ii) To critique the efficacy of MoGE's introduced alternative education platform in response to COVID-19 school closures and its impact on candidates' national examination results.

\subsection{THEORETICAL REVIEW OF LITERATURE}

\subsection{National Demographics}

Zambia is experiencing a large demographic shift and is one of the world's youngest countries by median age. The World Bank (2018) projects that this trend is expected to continue as the large youth population enters the reproductive age, which will put even more pressure on the demand for jobs, education, healthcare and other social services. In terms of age structure, the population under the age of 15 years and below accounts for about 50 per cent, while those under the age of 35years account for 70 per cent of the Zambian population (Masaiti et al., 2018). In terms of figures, $8,158,011$ are young people under the age of 15 years $(4,094,205$ males / 4,063,632 females), 8,876,572 persons between 15 and 64 years old $(4,461,085$ males / 4,415,487 females), 435,888 people above 64 years $(186,934$ males / 248,954 females) (World Bank, 2018) (CSO, 2017). In other words, the country overall has a young population, which makes the provision of educational services to this population to be of strategic importance to government (EFA, 2015). Critically, the financial commitments and allocations to the sector requires periodic reviews in order to guarantee required quality, accessibility, relevance, efficiency and inclusivity (Masaiti et al., 2018) (emphasis added).

\subsection{Lusaka District School Statistics}

The 2016 census survey revealed that Lusaka province has a total number of 106 public secondary schools and more than 140 primary schools spread in both urban and rural areas. It is noteworthy that the average number of schools in Lusaka district is more than the number of schools in the other districts within the province. As regards to the number of secondary and primary schools in Lusaka district, nothing much has changed from the 2010 census of population and housing, which shows that there were only 34 secondary and 90 primary schools in the district to contain the population of about 2,000,000 out of which $46.4 \%$ $(558,900)$ are of the school going youths below 16 years of age (Census Survey, $2010 \&$ 2015). Given the fact that the total population of Lusaka Province, according to Census Report (2015), is about 2, 000,000 and also that the total population of Lusaka district is higher than that of the other districts, it could be argued that there is only very little infrastructural space for which the rest of the $46.4 \%$ of the youthful population is competing for. Therefore, this would suggest that education quality service provision is compromised in one way or the other. This also would entail that others in this population may drop out of school for many a reason, or may be in school just to register presence, yet not attain the liberating intended education. Besides, notwithstanding the fact that the district also has a number of private and grant-aided schools which even outstrip the public ones, these institutions have a different management style and operational philosophy, which is largely anchored on capitalistic and neo-liberal ideological traditions, and therefore, still does not guarantee accessibility to most of the socioeconomically disadvantaged learners. Consequently, it is imperative to note that the responsibility of ensuring quality and equitable education provision per region is sacrosanctly vested in 
the government of the Republic of Zambia and that whatever the private sector is doing in this regard is a mere supplement to the government's effort (Hapompwe et al., 2020a).

The foregoing demographic analysis of the school going population relative to available infrastructural space clearly demonstrates an already troubled city in terms of education service delivery and requires liberation by way of infrastructure and other essential resources to match the growing demand.

\subsection{COVID - 19 and Academic Performance}

Academically, little is known about this pandemic which was discovered in China in 2019 (Chinazzi et al., 2020; Hopman, Allegranzi, \& Mehtar, 2020; Kraemer et al., 2020; Wu \& McGoogan, 2020; $\mathrm{Zu}$ et al., 2020). This is not because education is not directly affected by the effect of the COVID-19 epidemic but rather because studies in education rarely incorporate effects of disease on the effective provision of education to learners across the globe. The rate at which COVID-19 has rapidly been spreading has made every sector of human life to immediately feel its impact (Sintema, 2020). COVID - 19 has caused an indefinite closure of learning institutions in Zambia without any hope of re-opening them soon for progressive education information dissemination especially for the examination candidates who are scheduled to sit for final examinations in 3 months and 6 months' time respectively.

Educational institutions are mandated to use education as a tool for social transformation. The success of a school is measured by the quality of students it produces. The success of any educational institution is measured by the performance of its students in both academic and non-academic tests. This is supported by Yusuf (2008) when contending that the performance should not only be based in terms of test and examination results and student ability to apply what is learnt and the rate at which students move on to higher institution of learning, but should include other areas such as whether the students have acquired the survival skills. In spite of that, the use of students' achievement in academic work to assess the teacher's effectiveness has gained ground. The measure of academic performance as a symbol of school success can be traced way back from the Victorian period (Bell, 2013). Since then, academic performance has been used to grade schools and most importantly to determine one's career paths. The 'good schools' are acclaimed to be those that are able groom the students well enough to achieve the set standards. This is measured by use of students' academic performance both at school level and nationally. The importance of students' high performance has attracted the attention of the public, policymakers, educators, learners and ministry of education alike. DFE quoted in Gray \& Wilcox (1995, p.5) state that "better information about schools is also important for raising the standards. For example, publishing tables which compare the performance of schools has encouraged many schools to take a hard look at examination results their students achieve and how the school can help the pupils to do better." The level of students' performance has an impact on the roles played by education stakeholders. Students' achievement is influenced by a number of factors, primary among them being: inadequate resources low teachers' morale, teachers strikes, lack of parental involvement, the new grading system, lack of teachers and students' preparedness for change, lack of teachers' incentives, students not serious with their school work, poor leadership, the examination not addressing syllabi objectives and lack of support for homework (Molokomphale, 2014).

The foregoing paragraphs synopsized the critical role of learning institutions in shaping learners' character building and careers choices. There is strong emphasis on the fact that the basic and traditional standard for measuring performance of a school is by looking at the academic results of learners i.e. whether children at various levels are able to score better learner outcomes in different subjects to qualify them to different higher levels. It is quite well known that Zambia's performance in national examinations at grades 7,9 and 12 levels are mere averages in public schools and most private schools, and therefore the disruption by COVID-19 should cause a serious concern as to what it shall be of the results in 2020 final examinations. Quality education is the hallmark of the MoGE in Zambia and resonating with and aligned to these philosophical / pedagogical conceptions, the vision of the Ministry of General Education (MoGE) is to provide, "Quality, Lifelong Education for all which is Accessible, Inclusive and Relevant to an Individual, National and Global Value Systems" (MoGE, 2019). Motifs of equity, accessibility, quality, relevance, inclusivity, lifelong learning, therefore, must be the guiding principles in developing any education system, platform, curriculum, intervention or philosophy in order to sustain these fundamental blue prints for human and national development.

\subsection{Lusaka District's Academic Performance Table 1: Learners' Academic Performance}

Academic performance of learners is one of the most reliable indicators of quality education epitomizing quality productive inputs and optimal resources utilization. Table 1 below displays grades 9 and 12 learners' academic performance in Lusaka district during the period under review.

\begin{tabular}{|l|c|c|}
\hline & Grade 9 & Grade 12 \\
\hline 2015 & 76 & 71 \\
\hline 2016 & 75 & 72 \\
\hline 2017 & 77 & 65 \\
\hline 2018 & 72 & 60 \\
\hline 2019 & 78 & 61 \\
\hline Average & $75.6 \%$ & $65.8 \%$ \\
\hline
\end{tabular}

Source: DEBS Results Analysis Reports (2015-2019).

Table 1 above shows that during the period under review, grade 9 academic performance staggered at average of $75.6 \%$ while the grade 12 one hovered around $65.8 \%$ posting a variation of $9.8 \%$ between the two sections. These pass rates indicate a struggling subsector in meeting quality service delivery needs. The seemingly higher transitional rates for the junior secondary $(75.6 \%)$ is attributed to relatively better input factors (reduced congestion in classes, less duration of the syllabuses i.e. 2 years instead of 3 years at senior secondary school level, biological 
and pedagogical factors, among others, while the opposite of these are the reality in the senior secondary school level.

The grade 7 results though not indicated above have the similar pattern. While analyzing the 2016, 2017 and 2018 results for grades 7, 9 and 12, Lusaka Education District Office lamented that:

\begin{abstract}
"An analysis of our Grade 7, 9 and 12 pupils over the last two/three years $(2016,2017$ \& 2018) show a mixed performance of both poor and improved results obtained in terms of quality. However, one thing that remains constant across the 3 levels is that a much smaller percentage of learners obtain quality results (Division 1 and $1-4$ for grade 9 and 12 Learners."
\end{abstract}

The foregoing admission by the district office is a clear testimony that something fundamentally wrong was bedeviling the sector. But the most important point to note is that during the periods / years in question there was no single pre-mature closure at any time to constitute an attribution for such stressed learner outcomes. The problem currently is that there was a premature closure and in few months' time these candidates will be sitting for their examinations. In the study by Hapompwe et al., $(2020 \mathrm{~b})$, it was established that among the primary factors affecting learner achievements in Lusaka district are none availability of teaching-learning resources (books, computers, internet facilities, congestion in classes etc.).

\subsection{Technology in the Teaching-Learning Process}

Kapur (2018) stresses that technology is regarded as imperative to enhance learning. When students need to improve their skills and abilities regarding academic concepts, then internet serves as the imperative source of obtaining knowledge and information. In educational institutions, the primary objective is to ensure that students are able to acquire a satisfactory understanding of the academic concepts and produce desired academic outcomes. In textbooks, sometimes the knowledge is limited, hence, in order to acquire better understanding of the lesson plans, the students make use of the internet, take down notes and are able to acquire a better understanding. In the present existence, technology is even made use of in the preparation of projects, reports, and assignments. Earlier when technology was not adequately made use of in schools, then students used to prepare their assignments using stationary items. The use of technology also helps in correcting the errors and making the assignment appropriate. However, this notwithstanding, the Zambian education system is far below average in conclusive integration of ICT in the teaching-learning process as most schools even in Lusaka have only average number of computers with $1: 2$ ratios and without internet access. This implies that the school system has not in any way migrated to digital platforms in education service provision at the levels in question and therefore raises a lot of challenges in the wake of COVID-2019 school closures but education continuity.

\subsection{Theoretical Frameworks}

This publication is licensed under Creative Commons Attribution CC BY. http://dx.doi.org/10.29322/IJSRP.10.05.2020.p10175
Albert Bandura's (1986) Social learning theory or social cognitive theory focuses on what people learn from observing and interacting with other people. It is often called a bridge between behaviorist and cognitive learning theories because it encompasses attention, memory, and motivation. Bandura and his colleagues Dorrie and Sheila Ross continued to show that social modeling is a very effective way of learning. Social cognitive theory further claims that learning occurs in a social context with a dynamic and reciprocal interaction of the person, environment, and behavior. Social cognitive theory posits that people are not simply shaped by that environment; they are active participants in their environment. Bandura is highly recognized for his work on social learning theory and social cognitive theory. On the other hand, David Kolb's Experiential Learning theory posits that learning is a cyclical process that capitalizes on the participants' experiences for acquisition of knowledge. This process involves setting goals, thinking, planning, experimentation, reflection, observation, and review. By engaging in these activities, learners construct meaning in a way unique to themselves, incorporating the cognitive, emotional, and physical aspects of learning (Kolb, 1984).

The foregoing theories anchor the study and are on point that learning perceived to have greater possibility of achieving desirable learning outcomes is one in which learners take centerstage of the learning process socially, cognitively, experientially and is to some extent hands-on. In this case, it reduces a teacher to more of a facilitator than the dominator of the whole process. Further implying that all the pedagogical and learning materials i.e. traditional or digital must be organized in such a way which motivates a learner and enable them retain the concepts derived there from. Materials in e-learning must be dynamically intriguing and inspiring a learner to achieve greater skills by also being able to refer, rewind or retrieve information for further personal analysis.

However, it is noteworthy that the provision by MoGE in Edu.tv broadcast fundamentally fall short of the fundamental propositions of Bandura's and Kolb's theories as they lack effective or are not patterned after interactional and experiential pedagogies. Most of the lessons are delivered through TV broadcast with limited time and experiential materials thereby impairing the possibilities of learner retention, assimilation and absorption of lesson contents. It also implies that the teachers largely dominate the teaching process (lecture method), which contrary to contemporary teaching-learning pedagogies. The post-lesson evaluation questions, mostly, have only few minutes with hurried review of answers with the 30 minutes of the lesson - a reduction from the standard 40 minutes in normal learning time.

\subsection{Conceptual Framework}

The conceptual framework of a study is the system of concepts, assumptions, expectations, beliefs, and theories that support and informs research. Robson (2011) observe that it is a key part of the design. Miles et al., (1994) defined a conceptual framework as a visual or written product, one that explains, either graphically or in narrative form, the main things to be studied and the key factors which may be concepts or variables and the 
presumed relationships among them. This paper has been guided by a conceptual framework depicting the potential impediments to potential better learner achievements (dependent variables) as being inadequacy in dynamic ICT /digital platforms, inequity, environment, learner levels and inaccessibility (independent variables). Figure 1 below shows the paper's Conceptual Framework.

\section{Independent Variables $\quad$ Dependent Variable}

\begin{tabular}{|l|}
\hline Accessibility \\
\hline Equity \\
\hline Elatform Quality \\
\hline Eearner Level \\
\hline
\end{tabular}

Figure 1: Conceptual Framework

Source: Author's Construction (2020)

\subsection{METHODOLOGY}

The study was exploratory incorporating a qualitative paradigm and involved semi-structured key informant interviews of 3 district, provincial and MoGE HQ education officials; 4 primary and secondary school head teachers; 4 members of the parents and teachers' association, in Lusaka via telephone calls; 6 examination candidates; observation and monitoring of the Edu.tv lesson programme by MoGE, desk reviews and expert analysis. Lusaka district has a total of 124 public schools. Random and purposive sampling were the criteria involved to ensure sample representativeness and therefore validity, reliability and generalisability of findings.

\subsection{FINDINGS}

\subsection{Impact of COVID-19 on Academic Achievements}

The Ministry of General Education officials interviewed from the district to HQ shared similar sentiments that the education standards would be greatly affected by the COVID-19 pandemic as the sector was ill-prepared to put up any meaningful and result-oriented measures. They observed that the performance of learners at grades 7,9 and 12 had not been any better in the past years when all was relatively well i.e. no any disruption in the learning process and wondered how the situation would be this time around with the indefinite closure.

Besides, the parents/guardians of children who are in examination classes cried foul and wondered how their children will perform without full-time of learning knowing the low pace of material/syllabi coverage in public schools. Their sentiments were not any different from those of head teachers who equally observed catastrophic academic performance ahead unless other measures were to be put in place. The examination candidates too lamented the impact COVID-19 would occasion on their academic performance and prayed that the examiners would consider not setting examinations covering the whole syllabi as public schools were generally far from completing respective subject syllabi. They equally stressed that the schools were prematurely closed without taking term-end evaluations. Kapur (2018) observes that evaluation systems are regarded as essential sources that are used to improve the academic performance of the students. When teachers have taught a particular concept or a lesson plan to the students, then they are usually not aware that all the students have understood the concepts or not. For this purpose, it is vital to put into practice, proper evaluation systems. Evaluation of the performance and learning abilities of the students take place through organization of competitions, tests and giving them class and homework assignments which must be reinforced/marked. The grading systems should be fair and just. It is vital for the teachers to implement their evaluation systems on the basis of the performance of the students.

\subsection{Perspectives on MoGE's Edu.tv Learning Platform}

In response to the COVID-19 epidemic which led to the premature closure of all schools in Zambia, on $20^{\text {th }}$ March 2020, the MoGE in collaboration with the Ministry of Information and Broadcasting Services, announced the launch of an education platform on TV4 branded Edu.tv and dubbed: Education beyond classroom experience covering only secondary school levels i.e. grades 8 to 12 in total exclusion of the elementary and primary school levels, including grade 72020 examination classes. The launch was done via TV broadcast on $13^{\text {th }}$ April 2020. According to the time tables issued, lessons would be delivered throughout the week including weekends from morning to late hours and parents were urged to supervise their children in homes during the lesson delivery timings.

However, the following were views of interviewees in the field constituting the limitations and weaknesses of the launched alternative learning platform as regards its efficacy to panacea academic underperformance:

\section{i. $\quad$ Electricity load shedding:}

The parents mostly observed that the Edu.tv broadcast was greatly negatively impacted by the 15 -hour daily load shedding schedule which was effected by the power utility company, ZESCO Ltd observing that majority of public school pupils were from high density low income families who could not afford alternative sources of energy to access the lessons. In his comparative analysis of factors affecting learner achievements in 2015 Lusaka, using ANOVA, Hapompwe (2015) ascertained that access to electricity was among the primary factors in the taxonomy.

\section{ii. Accessibility:}

An observation was made that for one to access the Edu.tv lesson platform, they needed to have a TV set, Top Star decoder and a monthly subscription of K30 which was said to be unattainable to many as TV possession was not in the basic needs bracket among many Zambians. This view was further supported by a 
registered education organization in Zambia, National Action for Quality Education in Zambia (NAQUEZ) through their press statement of 12th April 2020 in which they observed that only $40 \%$ of the learners could be privileged to access the content due to poverty (News Diggers, 13th April, 2020). Inaccessibility to education is a direct assault on UNESCO's SDG \# 4 and the MoGE's blue prints coupled with the country's 2030 Vision.

\section{iii. Platform Quality:}

The cry of many was that the platform provided lacked diversity and variety; opining that as a method of trying to enhance accessibility, a lot of electronic and digital platforms could have been availed even away from the traditional mode of delivery as currently being provided. The interviewees shared the view that other platforms like Moodle, Virtual, Web-based, face book, note books, DVDs, CLANED, telegram, zoom etc. could have been provided so that the choice would have been broader for consumers coupled with the understanding that this would also help evade or circumvent the load shedding problem. Dynamism, experientialism and interactionism of the materials would allow for greater benefits to learners pedagogically as the current offering which is largely impersonal excites boredom and laziness to learners. Worse still, the lesson contact period has been reduced from the standard 40 minutes to 30 minutes thereby forcing teachers / learners to teach/learn at a pace not realistic for learner's content assimilation especially that there is no interaction, rewind, reciprocity etc.

\section{iv. Equity:}

It was shared that the Edu.tv broadcast materials did not take into learners with disabilities despite their innumerable statistics in Zambia. This, therefore, means that there is discrimination in the provision of education in Zambia which is against the constitution and international conventions to which Zambia subscribes. In buttressing this position, the Zambia Deaf Youth and Women President, Dr. Musukwa Frankson, stressed that Article 24 of the Convention on Rights of People with Disabilities emphasizes that people with disabilities have a right to education without discrimination and on the basis of equal opportunity and that the barriers presented by inaccessible to information will potentially negatively impact on learner with disabilities.

\section{v. Home Environment:}

The positioning of the the Edu.tv broadcast has ostensibly transferred the responsibility of managing and coaching the learning process to the parents/guardians whose majority education levels could not be supportive to the learners. Zambia's illiteracy levels are over $50 \%$ and most children in public schools of Lusaka are from homes whose parents/guardians have simply average education. Besides, the poverty levels in the city entail that the parents/guardians have to leave homes early morning to late afternoon in fending for livelihood and cannot hire a private tutor. Kapur (2018) identify poverty and illiteracy as being serious barriers in learners' better academic performance. Therefore, the problem of poverty is considered as one of the critical factors that hinder the academic performance of the students. When they do not possess the This publication is licensed under Creative Commons Attribution CC BY. essential resources to enhance their learning, then they are unable to improve their grades as well while the problem of illiteracy is also regarded as an impediment within the course of recognizing the significance of education (ibid) by parents/guardians.

\section{vi. Learner Levels:}

The head teachers and education officers observed that secondary school students by their psychological nature and syllabi material content, need professional coaching especially in deemed 'difficulty' subjects like mathematics, science, Biology, design and technology and computer studies. The absence of professional coaching is in a way a vacuum making allowance for undesirable learning outcomes. Kapur (2018) indicates that normally in subjects such as, mathematics and science, students need coaching. The main purpose of coaching is to make available extra classes for the students, so they are able to improve their academic performance. The poverty stricken individuals mainly possess low literacy skills or they are not educated, hence, they are unable to provide any kinds of instructions and training to their children. Students may achieve low scores, because they lack the help obtained from trained and experienced personnel.

\subsection{DISCUSSION OF FINDINGS}

It is conspicuously clear that the COVID-19 pandemic has disrupted the learning schedule of the entire education sector in Zambia but the adverse effect is anticipated on grades 7,9 and 12 whose summative examinations are due in 3 and 6 months' time though it is not yet clear as to when the 'self-isolation' measures may be lifted up to pave way for re-opening of schools. In the current scenario, the case and death tolls stand at 61 and 3 respectively (MoH Press Statement, 19th April, 2020). This scenario has put the education system in a quagmire and quandary as the regional body, SADC simply ended up with a synoptic diplomatic statement that "there is mobilization of regional support towards containment and mitigation of the socio-economic impact of COVID-19 pandemic on the SADC region; and partnering with the United Nations Educational, Scientific and Cultural Organization (UNESCO) to ensure continuity of education and learning programmes to avert the negative impact". However, there are no tangible activities in the education sector as purported by SADC to demystify the looming COVID-19 negative effect on education sector in general but examination students' academic performance in particular. The reduction in the contact hours of students without reduction in their syllabi materials, lack of assessments and coaching from professional staff coupled with none availability of learning materials are critical factors which will impede the performance of learners in the forthcoming examinations. This feeling of inadequacy by learners normally invoke examination fever. The fear resulting from examinations is an emotional state that affects the attention, concentration, thinking and memory (Kapur, 2018) and this has a bearing on the learners' ultimate performance.

On the other hand, there is enough demonstrable evidence epitomizing the limitations of government's introduced learning 
ISSN 2250-3153

platform Edu.tv broadcast to be a panacea for eminent compromised learner outcomes. It has been put clearly that the programme lacks stakeholder acceptability as no prior consultation was done with even parents/guardians; is not founded on equitable ethos as much as it is inaccessible and lacks the diversity, dynamism, broader choice, intriguing features, reciprocity, experientialism and contemporary pedagogical pedestal. In countries like Argentina and many others where similar programmes have been introduced, governments have offered to all learners from pre-school to university without any discrimination whatsoever on broader scale with free internet services. In Argentina, particularly, in addition to the 14 hours and 7 hours of TV and radio broad casts both on public and private radios / TVs, the government provides note books to learners who cannot access technology including those with learning disabilities throughout the country. These notebooks contain all the lessons and are given not only to learners but also to their parents/guardians for effective monitoring of their children (World Bank, 2020). In Zambia, however, the Ministry is printing CDs to distribute to other parts of the country although it is clear that an average person in the country has no access to a computer/TV and poverty levels in the country side is over $65 \%$. The poverty levels also are rooted in illiteracy which solidify the fact that an average learner's home environment is not supportive of their academic achievement. Thus, inaccessibility is prominent due to poverty and other barriers while the electricity load shedding for 15 hours has simply compounded the situation.

\subsection{CONCLUSION}

This study has demonstrated the eminent poor academic performance forthcoming from this year's grades 7, 9 and 12 classes arising from the disruption of the learning cycle due to public health measures to curb the further spread of COVID-19. There is also clarity that the impact would have been effectively minimised had government opted for a variety, divers, accessible, equitable, dynamic digital/electronic platforms which inspire all learners including parents to get involved in the teaching/learning process of their children/wards. The current platform (Edu.tv) is encumbered with the said challenges compounded by lack of electricity and stakeholder acceptability. E-learning platforms such as Moodle, virtue, Facebook, Webbased, CLANED, telegram, Zoom etc as supplements would have allowed for a broader choice along with reduced bandwidth internet.

\section{Author Biographies:}

1st Author: Chrine, C. Hapompwe

Lecturer - Cavendish University Zambia

Faculty of Arts Education \& Social Sciences

Ph.D. Candidate, Binary University, Malaysia.

chapompwe@cavendish.co.zm 2nd Author: Crispin Kukano

Lecturer - Cavendish University Zambia

Faculty of Arts Education \& Social Sciences

Ph.D. Candidate, UNISA, South Africa.

ckukano@cavendish.co.zm

3rd Author: Jacqueline Siwale

Lecturer - Cavendish University Zambia

Business \& Information Technology

Ph.D. Candidate, University of Zambia

jsiwale@cavendish.co.zm

\section{Corresponding Author:}

1st Author: Chrine, C. Hapompwe

chrinehapompwe7@gmail.com

\section{REFERENCES}

[1] Bandura, A. (1986). Social foundation of thought and action: A social cognitive theory. Englewood Cliffs, NJ: Prentice Hall.

[2] Bell, M. J. (2013). Define academic performance. : http://www.ehow.com

[3] Chinazzi, M., Davis, J. T., Ajelli, M., Gioannini, C., Litvinova, M., Merler, S., ... Viboud, C. (2020). The effect of travel restrictions on the spread of the 2019 novel coronavirus (COVID-19) outbreak. Science. https://doi.org/10.1126/science.aba9757

[4] Creswell, J. W. (2017). Educational Research: Planning, conducting, and evaluating quantitative and qualitative research. 4 th edition.

[5] Hapompwe, C. C., Karim, A. M. \& Kambikambi, T. T. (2020b). An Evaluation of Public Secondary Schools' Education Financing and Its Impact on Service Quality in Lusaka, Zambia. African Journal of Education and Practice, 5 (2), $19-32$.

[6] Hapompwe, C. C., Karim, A. M., Kambikambi, T. T. \& Milimo, V. (2020a). Assessment of Factors Accounting for Low Learner Outcomes in Core Subjects Among 5th and 9th Graders in Zambia's Public Schools. African Journal of Education and Practice, 6 (1), 1 - 18.

[7] Hopman, J., Allegranzi, B., \& Mehtar, S. (2020). Managing COVID-19 in Low and Middle Income Countries. JAMA. https://doi.org/10.1001/ jama.2020.4169

[8] Kapur, R. (2018). Factors Influencing Students Academic Performance in India. Research Gate.

[9] Kolb, D. A. (1984). Experiential learning: Experience as the source of learning and development. Englewood Cliffs, NJ: Prentice Hall.

[10] Kraemer, M. U., Yang, C. H., Gutierrez, B., Wu, C. H., Klein, B., Piggott, D. M., ... Brownstein, J. S. (2020). The effect of human mobility and control measures on the COVID-19 epidemic in China. Science. https://doi.org/10.1126/science.abb4218

[11] Masaiti, G. (ed.) (2018). Education in Zambia at Fifty Years of Independence and Beyond. Lusaka: UNZA Press.

[12] Ministry of Health Press Statement. Press Briefing On Covid-19 And Additional Preventive And Control Measures. Tuesday, 17th March 2020. Lusaka.

[13] MolokoMphale, L. and Mavis B. Mhlauli. (2014). An Investigation on Students Academic Performance for Junior Secondary Schools in Botswana. European Journal of Educational Research Vol. 3 (3), 111-127

[14] Sintema, E. J. (2020). Effect of COVID-19 on the Performance of Grade 12 Students: Implications for STEM Education. EURASIA Journal of Mathematics, Science and Technology Education, 16(7).

[15] UNESCO. (2018). Annual Report (11th Ed.) Lusaka: UNESCO. 
ISSN 2250-3153

[16] World Bank Group. (2018). The World Bank Group in Zambia - Report No. 128467-ZA. Lusaka.

[17] Wu, Z., \& McGoogan, J. M. (2020). Characteristics of and important lessons from the coronavirus disease 2019 (COVID-19) outbreak in China: summary of a report of 72314 cases from the Chinese Center for Disease Control and Prevention.

[18] Yusuf, A. F. (2012). Influence of principals' leadership styles on students' academic achievement in secondary schools. Journal of Innovative Research in Management and Humanities, 3(1), 113 -121.

[19] Zambia's 7th National Development Plan (7NDP) (2017-2021).

[20] Zambia National Education Coalition (ZANEC) 2019 Press Statement.

[21] Zambia's Vision 2030: Education for All 2015 National Review Report:

[22] Zu, Z. Y., Jiang, M. D., Xu, P. P., Chen, W., Ni, Q. Q., Lu, G. M., \& Zhang, L. J. (2020). Coronavirus disease 2019 (COVID-19): A perspective from China. Radiology. 